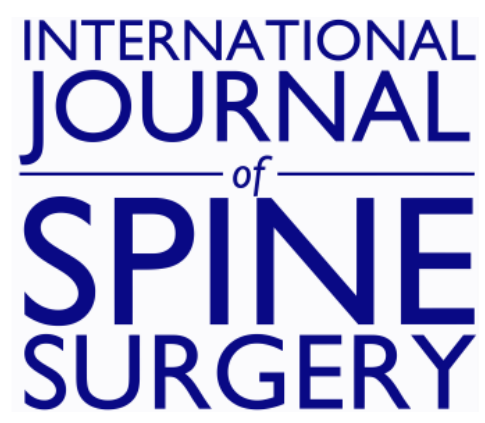

\title{
Comparison of Clinical Outcome and Radiologic Parameters in Open TLIF Versus MIS-TLIF in Single- or Double-Level Lumbar Surgeries
}

Hitesh N. Modi and Utsab Shrestha

Int J Spine Surg published online 22 September 2021

http://ijssurgery.com/content/early/2021/09/20/8126

This information is current as of April 26, 2023.

Email Alerts Receive free email-alerts when new articles cite this article. Sign up at:

http://ijssurgery.com/alerts

The International Journal of Spine Surgery

2397 Waterbury Circle, Suite 1,

Aurora, IL 60504, Phone: +1-630-375-1432 


\title{
Comparison of Clinical Outcome and Radiologic Parameters in Open TLIF Versus MIS-TLIF in Single- or Double-Level Lumbar Surgeries
}

\author{
HITESH N. MODI, MS, PHD, UTSAB SHRESTHA, MS \\ Department of Spine Surgery, Zydus Hospital and Healthcare Research Pvt Ltd, Ahmedabad, Gujarat, India
}

\begin{abstract}
Purpose: The objective of this study was to compare clinical and radiologic parameters between minimally invasive surgery-transforaminal lumbar interbody fusion (MIS-TLIF) and open TLIF.

Methods: Data of 145 patients who underwent single- or double-level TLIF procedures with an open $(\mathrm{n}=76)$ or a MIS $(n=69)$ technique were analyzed. Average operation time, estimated blood loss, and hospital stay were compared between open TLIF and MIS-TLIF. Improvement in clinical scores was analyzed using visual analog scale (VAS) and Oswestry Disability Index (ODI) scores in both groups and statistically compared using $t$ tests. Radiologic parameters, such as lumbar lordosis, focal lordosis at the index level, and pelvic incidence (PI), were calculated at preoperative, postoperative, and final follow-up for comparison. The differences in improvement between open and MIS groups were analyzed using unpaired $t$ tests.

Results: Average follow-up was $35.8 \pm 15.4$ months in open TLIF and $37.9 \pm 14.4$ months in MIS-TLIF. The average blood loss and operation times were higher and hospital stay was less in MIS-TLIF compared to open TLIF. VAS scores were improved from preoperative $(8.5 \pm 0.6)$ to postoperative $(2.1 \pm 0.8)$ and preoperative $(8.4 \pm 0.8)$ to postoperative $(2.0 \pm 0.7)$ in open TLIF and MIS-TLIF, respectively $(P<.0001)$, and ODI scores were improved from preoperative $(55.2 \pm 5.2)$ to postoperative $(22.5 \pm 4.3)$ and preoperative $(56.7 \pm 4.9)$ to postoperative $(22.0 \pm 5.0)$ in open TLIF and MIS-TLIF, respectively $(P<.0001)$. Similarly, there were significant improvements in lumbar lordosis and focal lordosis at the index level with a difference of $3.9^{\circ}$ and $2.5^{\circ}$, respectively, in open TLIF and $4.0^{\circ}$ and $2.9^{\circ}$, respectively, in MIS-TLIF. However, there were no differences in PI in both groups. There were $9(11.8 \%)$ and $9(13 \%)$ complications encountered in open TLIF and MIS-TLIF, respectively. Two patients from open TLIF and 5 from MISTLIF had to undergo revision surgeries without any statistical difference.

Conclusions: Open TLIF and MIS-TLIF are equally efficient surgical techniques with similar clinical and radiologic outcomes. MIS-TLIF is associated with less intraoperative blood loss and hospital stay; however, it increases operation time significantly.
\end{abstract}

Research Article

Keywords: MIS-TLIF, open TLIF, clinical outcome, radiologic outcome, comparison

\section{INTRODUCTION}

Lumbar interbody fusion with instrumentation is an effective surgical option to stabilize the painful motion segment and provides an indirect decompression of the neural elements, correcting lordosis and deformity. ${ }^{1}$ Five different types of lumbar interbody fusion procedures are performed by spine surgeons: posterior lumbar interbody fusion, transforaminal lumbar interbody fusion (TLIF or minimally invasive TLIF [MIS-TLIF]), oblique lumbar interbody fusion (OLIF), anterior lumbar interbody fusion, and lateral lumbar interbody fusion (LLIF/XLIF). ${ }^{2}$ However, there is no clearcut definitive evidence for 1 approach being superior to another in terms of fusion or clinical outcomes. However, there are certainly some advantages for using 1 technique over another, and therefore specific indications for each technique have been described in the literature. ${ }^{2}$

Among them, the TLIF technique was first reported by Harms and Rolinger ${ }^{3}$ in 1982. Thereafter, TLIF has been increasingly used in a variety of lumbar diseases, including degenerative lumbar disc diseases, spondylolisthesis, degenerative scoliosis, and spinal instability. ${ }^{4,5}$ Although TLIF is an effective procedure, extensive stripping of the paravertebral muscles and prolonged retraction are required for adequate exposure of the surgical 
field. ${ }^{6,7}$ Iatrogenic muscle damage can lead to atrophy of the paraspinal muscles and chronic postoperative low back pain. ${ }^{8,9}$ Additionally, TLIF may not be as effective as OLIF or XLIF to correct coronal imbalance and restore lordosis.

The MIS-TLIF procedure was first described by Foley et $\mathrm{al}^{10}$ in 2003. Its popularity has been increasing since then. Favorable outcomes of MISTLIF have been reported for various surgical indications. ${ }^{11-13}$ The disadvantage includes exposure to ionizing radiation. ${ }^{14}$ Moreover, longer surgical time has also been reported for MIS-TLIF, at least in a few cases, and can be attributed to a narrow working channel, which could be a reflection of technical differences compared to open TLIF; however, some authors associate this with a significant learning curve. ${ }^{15-18}$ The maintenance of sagittal balance while performing the TLIF procedure has been emphasized in the literature as related to both clinical outcome and adjacent segment degeneration. ${ }^{19}$ Although several studies have compared the functional outcome between open TLIF and MIS-TLIF, only a few have compared the correction of radiologic parameters. ${ }^{20-23}$

The purpose of this study was to compare the clinical, perioperative, and radiologic outcomes between MIS-TLIF and conventional open TLIF procedures during single- or double-level (shortsegment) lumbar fusion. This study also focuses on spine sagittal alignment parameters after the fusion.

\section{MATERIALS AND METHODS}

A retrospective analysis of total 145 patients who underwent single- or double-level TLIF procedures between January 2016 and December 2018 was carried out. All subjects were operated for either open TLIF $(\mathrm{n}=76)$ or MIS-TLIF $(\mathrm{n}=69)$ procedures with the following inclusion criteria: (1) mechanical low back pain and radicular leg symptoms, (2) lack of response to conservative therapy for at least 6 weeks, (3) age between 18 and 80 years, (4) single- or double-level (short-segment) involvement, and (5) magnetic resonance imaging (MRI) showing 1- or 2-level lumbar stenosis with facetal hypertrophy or grade 1 to 2 spondylolisthesis. Exclusion criteria included 3-level or higher surgeries, history of previous spine surgeries, revision surgeries, cauda equina syndrome, spine infection or pathology, significant lumbar deformity requiring correction, and lack of lateral lumbosacral $\mathrm{X}$-ray on 3 different occasions or poor-quality $\mathrm{X}$ - rays. All the open TLIF and MIS-TLIF procedures were performed by a single spine surgeon in a single center. Selection of open TLIF or MIS-TLIF was decided by patients after explaining the procedures and discussing the patients' financial constraints.

Operation time in minutes, estimated blood loss (EBL), length of stay, perioperative morbidity, and complications were collected prospectively in all surgeries. All patients were followed up at 1, 3, 6, and 12 months and yearly thereafter. Clinical improvement was analyzed using visual analog scale (VAS) and Oswestry Disability Index (ODI) scores at preoperative, at 1-month postoperative, and at the final follow-up.

\section{SURGICAL METHOD}

\section{Techniques for MIS-TLIF}

In MIS-TLIF, decompression was considered on the more symptomatic side at the affected level. The level of operation was confirmed under anteroposterior and lateral views of the C-arm. A horizontal line was also drawn joining the midpoint of the right and left pedicle on each vertebra. Right and left vertical lines were drawn at the lateral part of the pedicles. These lines were used to take an entry into the pedicles with Jamshidi needles for screw insertion. An approximate $25-\mathrm{mm}$ vertical incision was kept just $10 \mathrm{~mm}$ lateral to the vertical pedicle line at the appropriate level. Serial tubular dilators and a retractor tube were inserted to reach to the facet joint, which was fixed with a table rod-clamp. A monopolar cautery and disc forceps was used to expose the facet joint. Facetectomy was done using a high-speed burr and osteotome under a microscope. The ligamentum flavum was removed with Kerrison rongeurs to assess the dura and nerve root. Contralateral decompression was also carried out by an over-the-top technique if required. The traversing nerve and dura were retracted medially to expose the target disc, and a thorough discectomy was performed. Endplate preparation was done, and an appropriately size TLIF cage was inserted along with local bone grafts. Percutaneous pedicle screw fixation was performed under the $\mathrm{C}$-arm guidance.

\section{Techniques for Open TLIF}

The level to be operated on was confirmed under anteroposterior and lateral views of the C-arm. After midline posterior incision, subperiosteal dissection was carried out to the tips of the spinous 
processes to expose the entry points for the pedicle screws. Insertion of pedicle screws and the rodscrew construct was performed, followed by laminectomy and facetectomy on the symptomatic side to achieve decompression at the affected level. Discectomy was done by retracting the traversing nerve root and dura medially, and the TLIF cage was inserted with local bone grafts.

\section{Radiologic Measurements}

Pelvic incidence (PI) angle was measured between 2 lines: 1 from the midpoint of the upper sacral endplate to the hip axis and 1 perpendicular to the upper sacral endplate. Focal lordosis is the angle between upper and lower endplates, composed of the disc space. Focal lordosis of the disc space was measured where the TLIF cage was inserted. Similarly, the lumbar lordosis angle is defined as the angle between the upper endplate of the L1 vertebra and upper endplate of the sacrum. In our study, perpendicular lines were drawn from these lines in Microsoft PowerPoint, and the angle was measured manually between 2 perpendicular lines. The measurement of parameters of sagittal balance was done by a single observer from the lumbosacral radiographs of 3 different occasions: preoperative, immediately postoperative, and final follow-up. Measurement of angles was recorded 3 times at an interval of at least 1 week between 2 measurements, and average values were calculated.

\section{Statistical Analysis}

Statistical analysis for clinical and radiologic parameters was performed using SPSS software (version 17, SPSS, Chicago, Illinois) with $t$ tests and $\chi^{2}$ tests.

\section{RESULTS}

Of 145 patients, 76 and 69 were in the open TLIF group and MIS-TLIF group, respectively. The average age of patients in the open TLIF and MIS-TLIF groups was $51.5 \pm 14.0$ years and 51.2 \pm 12.2 years, respectively. The average follow-up was $35.8 \pm 15.4$ months in the open TLIF group and $37.9 \pm 14.4$ months in the MIS-TLIF group. There were 35 males and 41 females in the open TLIF group and 31 males and 38 females in the MIS-TLIF group, suggesting no difference in both groups $\left(P=.891, \chi^{2}\right.$ test $)$ regarding sex distribution. There were 34 single-level and 42 double-level
Table 1. Number of patients in each group with single- or double-level disc herniation.

\begin{tabular}{lccc}
\hline Group & Open TLIF & MIS-TLIF & Total \\
\hline No. of patients & 76 & 69 & 145 \\
Age, mean \pm SD, y & $51.5 \pm 14.0$ & $51.2 \pm 12.2$ & $51.4 \pm 13.1$ \\
Male/Female, $\mathrm{n}$ & $35 / 41$ & $31 / 38$ & $66 / 79$ \\
Follow-up, mean \pm SD, mo & $35.8 \pm 15.4$ & $37.9 \pm 14.4$ & $36.8 \pm 14.9$ \\
Single-level TLIF, n & 34 & 45 & 79 \\
L1-L2 & 2 & 0 & 2 \\
L2-L3 & 1 & 0 & 1 \\
L3-L4 & 3 & 4 & 7 \\
L4-L5 & 21 & 28 & 49 \\
L5-S1 & 7 & 13 & 20 \\
Double-level TLIF, n & 42 & 24 & 66 \\
L1-L2, L2-L3 & 0 & 0 & 0 \\
L2-L3, L3-L4 & 4 & 3 & 7 \\
L3-L4, L4-L5 & 14 & 9 & 23 \\
L4-L5, L5-S1 & 24 & 12 & 36 \\
\hline
\end{tabular}

Abbreviations: MIS-TLIF, minimally invasive surgery-transforaminal lumbar interbody fusion; TLIF, transforaminal lumbar interbody fusion.

surgeries in the open TLIF group and 45 singlelevel and 24 double-level surgeries in the MIS-TLIF group, suggesting that the open TLIF group had significantly higher double-level surgeries $(P=.013$, $\chi^{2}$ test). Involvement of levels and demographics are shown in Table 1.

Average operation time, EBL, and hospital stay were $130.8 \pm 15.2$ minutes, $289.7 \pm 58.5 \mathrm{~mL}$, and $5.5 \pm 1.3$ days, respectively, in the open TLIF group and $170.1 \pm 18.8$ minutes, $139.6 \pm 42.2 \mathrm{~mL}$, and 4.9 \pm 0.8 days, respectively, in the MIS-TLIF group (Figure 1). There was significantly longer operation time $(P<.0001$, unpaired $t$ test $)$ and significantly less EBL $(P<.0001$, unpaired $t$ test $)$ in the MISTLIF group compared to the open-TLIF group. Average hospital stay was also longer in the openTLIF group than the MIS-TLIF group $(P=.002$, unpaired $t$ test) (Table 2).

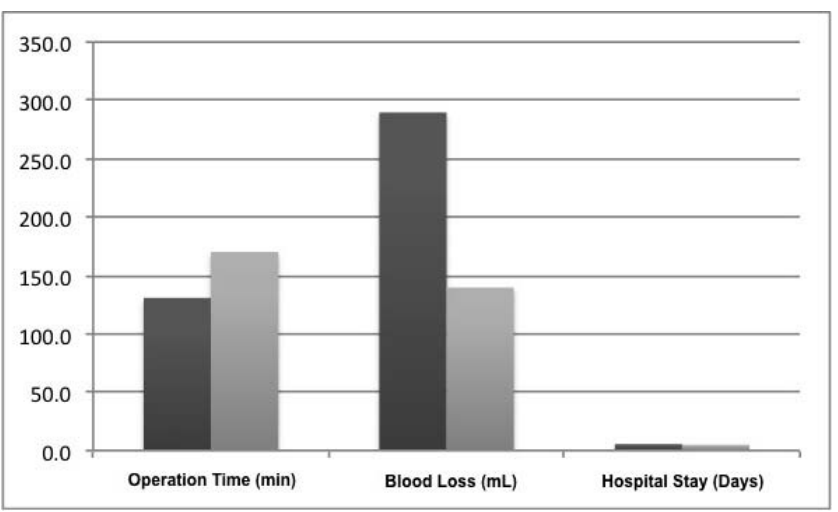

Figure 1. Bar diagram of average operation time (minutes), intraoperative blood loss ( $\mathrm{mL}$ ) and hospital stay (days) for open TLIF and MIS-TLIF group (dark area is for open TLIF, and lighter area is for MIS-TLIF). TLIF indicates transforaminal lumbar interbody fusion; MIS-TLIF, minimally invasive surgerytransforaminal lumbar interbody fusion. 
Table 2. Average operation time, blood loss, and hospital stay in both groups and according to single- or double-level involvement.

\begin{tabular}{lccc}
\hline & $\begin{array}{c}\text { Open TLIF, } \\
\text { Mean } \pm \text { SD }\end{array}$ & $\begin{array}{c}\text { MIS-TLIF, } \\
\text { Mean } \pm \text { SD }\end{array}$ & $\boldsymbol{P}$ Value \\
\hline Operation time, min & $130.8 \pm 15.2$ & $170.1 \pm 18.8$ & $<.0001$ \\
Single level & $121.8 \pm 8.0$ & $165.1 \pm 16.6$ & \\
Double level & $139.4 \pm 15.6$ & $181.5 \pm 18.9$ & \\
Estimated blood loss, mL & $289.7 \pm 58.5$ & $139.6 \pm 42.2$ & $<.0001$ \\
Single level & $274.2 \pm 59.8$ & $128.4 \pm 38.1$ & \\
Double level & $304.4 \pm 53.1$ & $165.2 \pm 40.7$ & \\
Hospital stay, d & $5.5 \pm 1.3$ & $4.9 \pm 0.8$ & .002 \\
Single level & $5.3 \pm 1.2$ & $4.8 \pm 0.8$ & \\
Double level & $5.7 \pm 1.3$ & $5.3 \pm 0.9$ & \\
\hline
\end{tabular}

Abbreviations: MIS-TLIF, minimally invasive surgery-transforaminal lumbar interbody fusion; TLIF, transforaminal lumbar interbody fusion.

Clinically average preoperative, postoperative, and final follow-up VAS scores were $8.5 \pm 0.6,2.1$ \pm 0.8 , and $2.2 \pm 0.7$, respectively, in the open TLIF group and $8.4 \pm 0.8,2.0 \pm 0.7$, and $2.0 \pm 0.8$, respectively, in the MIS-TLIF group. Similarly, average preoperative, postoperative, and final follow-up ODI scores were 55.2 \pm 5.2, $22.5 \pm 4.3$, and $22.6 \pm 4.4$, respectively, in the open TLIF group and $56.7 \pm 4.9,22.0 \pm 5.0$, and $22.4 \pm 4.7$, respectively, in the MIS-TLIF group (Table 3). There was significant clinical improvement in VAS and ODI scores postoperatively in both groups $(P<$ .0001 , paired $t$ test), and all changes were maintained at the final follow-up (Figure 2). However, there was statistically no difference in improvement in both groups $(P=.0612$ for VAS and $P=.820$ for

Table 3. Preoperative, postoperative, and final follow-up clinical visual analog scale (VAS) and Oswestry Disability Index (ODI) scores and radiologic parameters using lumbar lordosis (LL), pelvic incidence (PI), and focal lordosis at the index level (FL) in both groups.

\begin{tabular}{lcccc}
\hline & $\begin{array}{c}\text { Open TLIF, } \\
\text { Mean } \pm \text { SD }\end{array}$ & $\boldsymbol{P}$ Value & $\begin{array}{c}\text { MIS-TLIF, } \\
\text { Mean } \pm \text { SD }\end{array}$ & $\boldsymbol{P}$ Value \\
\hline VAS & & & & \\
$\quad$ Preoperative & $8.5 \pm 0.6$ & & $8.4 \pm 0.8$ & \\
$\quad$ Postoperative & $2.1 \pm 0.8$ & $<.0001$ & $2.0 \pm 0.7$ & $<.0001$ \\
$\quad$ Final follow-up & $2.2 \pm 0.7$ & $<.0001$ & $2.0 \pm 0.8$ & $<.0001$ \\
ODI & & & & \\
$\quad$ Preoperative & $55.2 \pm 5.2$ & & $56.7 \pm 4.9$ & \\
$\quad$ Postoperative & $22.5 \pm 4.3$ & $<.0001$ & $22.0 \pm 5.0$ & $<.0001$ \\
$\quad$ Final follow-up & $22.6 \pm 4.4$ & $<.0001$ & $22.4 \pm 4.7$ & $<.0001$ \\
LL, & & & & \\
$\quad$ Preoperative & $40.3 \pm 10.9$ & & $43.4 \pm 11.5$ & \\
$\quad$ Postoperative & $44.2 \pm 11.1$ & $<.0001$ & $47.4 \pm 12.1$ & $<.0001$ \\
$\quad$ Final follow-up & $44.7 \pm 11.2$ & $<.0001$ & $46.9 \pm 12.1$ & $<.0001$ \\
PI, ${ }^{\circ}$ & & & & \\
$\quad$ Preoperative & $50.7 \pm 10.8$ & & $54.6 \pm 10.4$ & \\
$\quad$ Postoperative & $50.6 \pm 10.8$ & .584 & $54.7 \pm 10.0$ & .472 \\
$\quad$ Final follow-up & $50.6 \pm 10.8$ & .559 & $54.5 \pm 10.1$ & .679 \\
FL, ${ }^{\circ}$ & & & & \\
$\quad$ Preoperative & $6.8 \pm 5.8$ & & $7.7 \pm 5.1$ & \\
$\quad$ Postoperative & $9.3 \pm 5.9$ & $<.0001$ & $10.6 \pm 5.1$ & $<.0001$ \\
$\quad$ Final follow-up & $9.6 \pm 5.7$ & $<.0001$ & $9.7 \pm 4.8$ & $<.0001$ \\
\hline
\end{tabular}

Abbreviations: MIS-TLIF, minimally invasive surgery-transforaminal lumbar interbody fusion; TLIF, transforaminal lumbar interbody fusion.

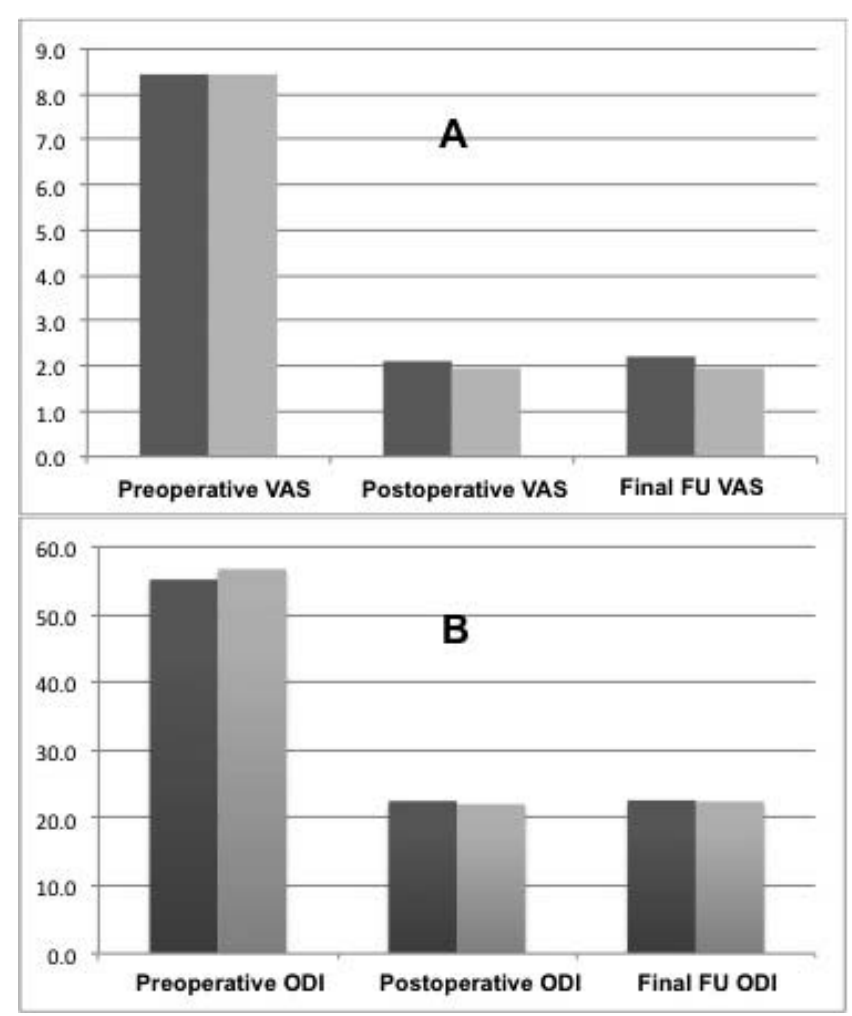

Figure 2. Bar diagram of average preoperative, postoperative, and final followup for (A) visual analog scale (VAS) and (B) Oswestry Disability Index (ODI) in open TLIF and MIS-TLIF (dark area is for open TLIF, and lighter area is for MISTLIF). TLIF indicates transforaminal lumbar interbody fusion; MIS-TLIF, minimally invasive surgery-transforaminal lumbar interbody fusion.

ODI). In the open TLIF group, average preoperative, postoperative, and final lumbar lordosis were $40.3^{\circ} \pm 10.9^{\circ}, 44.2^{\circ} \pm 11.1^{\circ}$, and $44.7^{\circ} \pm 11.2^{\circ}$, respectively; PI was $50.7^{\circ} \pm 10.8^{\circ}, 50.6^{\circ} \pm 10.8^{\circ}$, and $50.6^{\circ} \pm 10.8^{\circ}$, respectively; and, similarly, focal lordosis at the index level was $6.8^{\circ} \pm 5.8^{\circ}, 9.3^{\circ} \pm$ $5.9^{\circ}$, and $9.6^{\circ} \pm 5.7^{\circ}$, respectively (Figure 3 ). There was significant improvement in lumbar lordosis $(P$ $<.0001$, paired $t$ test) and focal lordosis at the index level $(P<.0001$, paired $t$ test $)$ postoperatively; however, there was no significant difference in PI ( $P$ $=0.584$, paired $t$ test). In the MIS-TLIF group, average preoperative, postoperative, and final lumbar lordosis were $43.4^{\circ} \pm 11.5^{\circ}, 47.4^{\circ} \pm 12.1^{\circ}$, and $46.9^{\circ} \pm 12.1^{\circ}$, respectively; PI was $54.6^{\circ} \pm 10.4^{\circ}$, $54.7^{\circ} \pm 10.0^{\circ}$, and $54.5^{\circ} \pm 10.1^{\circ}$, respectively; and, similarly, focal lordosis at the index level was $7.7^{\circ} \pm$ $5.1^{\circ}, 10.6^{\circ} \pm 5.1^{\circ}$, and $9.7^{\circ} \pm 4.8^{\circ}$, respectively. There was significant improvement in lumbar lordosis $(P<.0001$, paired $t$ test $)$ and focal lordosis at the index level $(P<.0001$, paired $t$ test $)$ postoperatively; however, there was statistically no difference in PI $(P=0.472$, paired $t$ test) (Table 3$)$. 


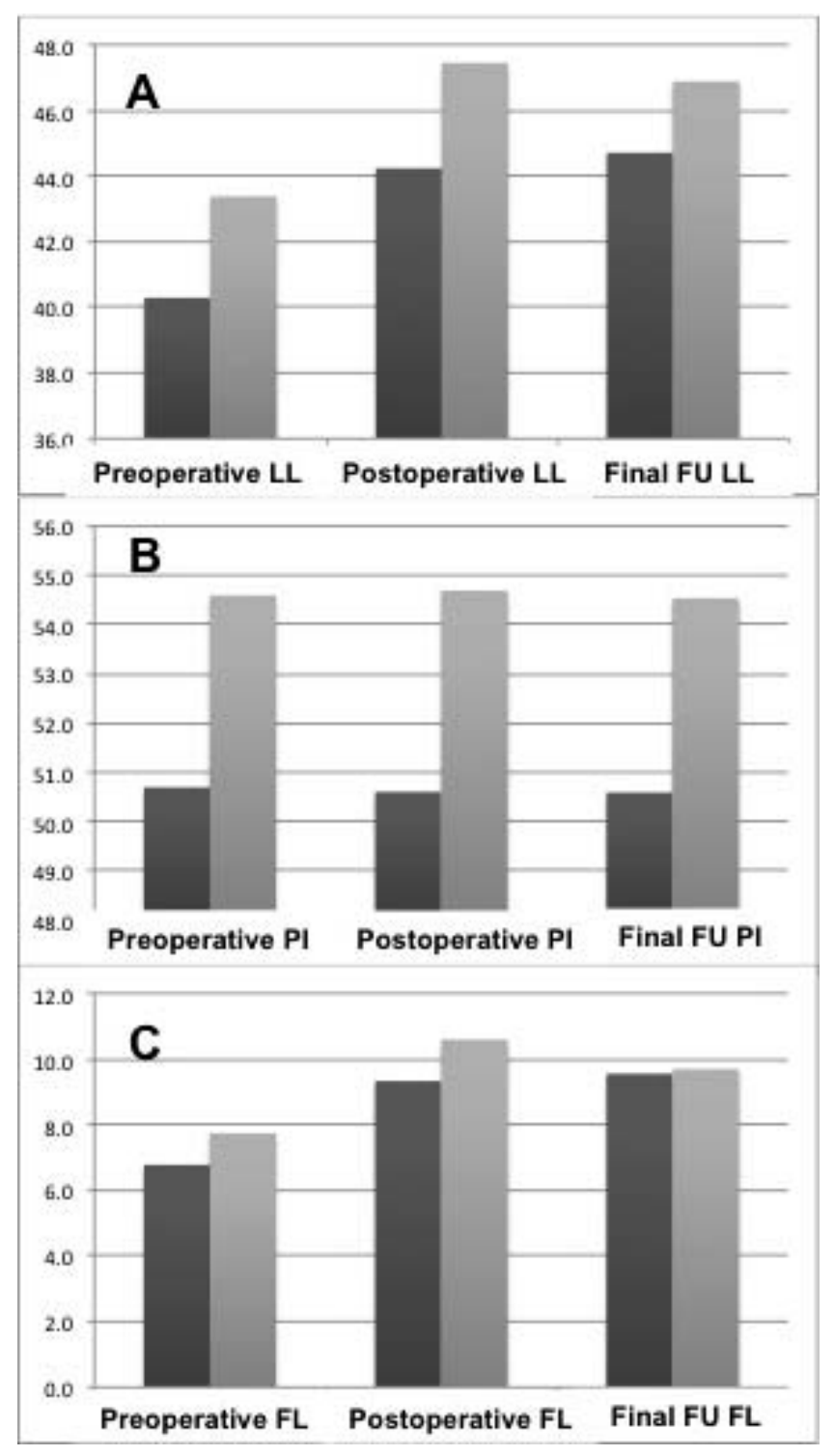

Figure 3. Bar diagram of average preoperative, postoperative, and final followup for (A) lumbar lordosis (LL), (B) pelvic incidence (PI), and (C) focal lordosis at the index level (FL) in open TLIF and MIS-TLIF (dark area is for open TLIF, and lighter area is for MIS-TLIF). TLIF indicates transforaminal lumbar interbody fusion; MIS-TLIF, minimally invasive surgery-transforaminal lumbar interbody fusion.

There were total 9 complications each in the open TLIF (11.8\%) and MIS-TLIF (13\%) groups (Table 4). In the open TLIF group, there were $4,2,1,1$, and 1 patients with persistent numbness, postoperative radicular symptoms, wound infection, mild back-out of cage, and foot drop postoperatively. Two patients who had postoperative wound infection and foot drop due to a malpositioned pedicle screw at L3 required revision surgery. Other patients were treated conservatively, as there was no obvious cause found on repeat imaging. A patient with mild back-out of cage was asymptomatic and therefore
Table 4. Complications in both groups.

\begin{tabular}{llll}
\hline Complications & Open TLIF & MIS-TLIF & Total \\
\hline Total, n (\%) & $9(11.8)$ & $9(13)$ & $18(12.4)$ \\
Persistent numbness & 4 & 1 & 5 \\
Radicular symptoms & 2 & 1 & 3 \\
Infection & 1 & 1 & 2 \\
Cage back-out & 1 & 3 & 4 \\
Hematoma & 0 & 1 & 1 \\
Dural tear & 0 & 1 & 1 \\
Screw breakage & 0 & 1 & 1 \\
Foot drop (neurologic) & 1 & 0 & 1 \\
Revision required, n $(\%)$ & $2(2.7)$ & $5(7.2)$ & $7(4.8)$ \\
\hline
\end{tabular}

Abbreviations: MIS-TLIF, minimally invasive surgery-transforaminal lumbar interbody fusion; TLIF, transforaminal lumbar interbody fusion.

was treated conservatively. In the MIS-TLIF group, 3 patients had back-out of cage, of which 2 had revision surgery in the form of the removal of the cage, while 1 was treated conservatively, as there was no symptoms. In the MIS-TLIF group, 1 patient each had symptoms of postoperative numbness, postoperative radicular pain, wound infection, dural tear, hematoma, and screw breakage. The patients who had screw breakage, hematoma, and infection were reoperated, while others were treated conservatively. There was no difference found in terms of complications and revisions in both groups ( $P=.826$ for complications and $P=.146$ for revisions, $\chi^{2}$ test).

\section{DISCUSSION}

TLIF is an established technique for the treatment of various lumbar disc degenerative diseases, instability (spondylolisthesis), severe lumbar stenosis, and lumbar disc herniation for which conservative treatment is ineffective. Since there is less violation of bony structure and spinal musculature, the MIS-TLIF technique is currently as widely accepted as the open TLIF technique. ${ }^{24,25}$ Moreover, less intraoperative blood loss and less tissue trauma during MIS-TLIF speeds up postoperative recovery of the patient, leading to earlier discharge from the hospital. Our study has shown that patients in the MIS-TLIF group had significantly shorter length of hospital stay than those in the open TLIF group (although the difference is minimal). Thus, MIS-TLIF can help reduce the total expenditure for surgery due to the shorter length of the stay in the hospital. ${ }^{26}$ In most metaanalyses, the length of the patient's hospital stay with the MIS-TLIF technique was found to be significantly shorter. Tian et $\mathrm{al}^{27}$ reported a difference of 2.7 days, while $\mathrm{Hu}$ et $\mathrm{al}^{28}$ in their meta- 
analysis observed a range of between 1.3 and 10.6 days. Lin et $\mathrm{al}^{29}$ analyzed 18 studies reporting a significant difference of 1.3 days less for MIS-TLIF.

In our study, EBL was $289.7 \pm 58.5 \mathrm{~mL}$ and $139.6 \pm 42.2 \mathrm{~mL}$ in the open TLIF and MIS-TLIF groups, respectively, suggesting significantly less blood loss in the MIS-TLIF group $(P<.0001$, unpaired $t$ test). Ahmed et $\mathrm{al}^{30}$ found that EBL was $568.18 \mathrm{~mL}$ in the open TLIF group and $247.82 \mathrm{~mL}$ in the MIS-TLIF group. The difference was significant $(P<.00001$, unpaired $t$ test $)$. The mean length of stay was 5.05 days in the MIS-TLIF group versus 6.92 days in the open TLIF group. The difference was significant. Mean operative time was $130.8 \pm 15.2$ minutes and $170.1 \pm 18.8$ minutes in the open TLIF and the MIS-TLIF group, respectively, in our study. Mean operative time in the MIS-TLIF and open TLIF groups was mentioned as 375 minutes and 161 minutes, respectively, by Sulaiman et $\mathrm{al}^{31}$ and as 368.3 minutes and 252.5 minutes, respectively, by Hey and Hee. ${ }^{32}$ Operative time is certainly longer in the MIS-TLIF group, as the working channel is narrow and the surgeon has to develop depth sensation to work through the tube, making the learning curve long. ${ }^{33}$ Although the operative time is higher in the MIS-TLIF group of patients, less tissue trauma, preservation of the midline structure, and lesser osteotomy make the surgery superior with less blood loss, an earlier return to home, and less back and leg pain. Moreover, as the surgery is done under IITV guidance, the time required for taking IITV images has a significant contribution to total operative time. Our study also proved that although operation time is longer in the MIS-TLIF group than in the open TLIF group, it results in less EBL and less tissue trauma, favoring its acceptability. It also naturally understood that double-level surgery in open TLIF or MIS-TLIF would require a longer operation time, more EBL, and a longer hospital stay, as shown in Table 2; however, it did not make a significant difference with regard to the purpose of this study. Therefore, in terms of short-segment (up to two levels) surgery, further detailed analysis regarding single- or double-level surgery outcome would be of little significance and so was not included in the study.

Better VAS and ODI outcomes result from shorter durations of intramuscular pressure and less tissue injury caused by a more experienced surgeon, but long operation time is associated with poor VAS and ODI scores when surgery is performed by surgeons in the early stage of the learning curve. ${ }^{34-38}$ A multicenter randomized study conducted by Alamin et $\mathrm{al}^{39}$ to evaluate the effect of MIS-TLIF versus open TLIF on paraspinal musculature using MRI showed that both quantitative and qualitative measures of edema in the multifidus were significantly less in the MIS-TLIF group, which is consistent with less muscle injury. In our study, we found significant improvement in both VAS and ODI scores postoperatively in both groups, which were maintained at the final follow-up. Hammad et $\mathrm{al}^{30}$ found that the complication rate was lower with MIS-TLIF (11.3\%) versus open TLIF (14.2\%) but not statistically significantly different $(P>.05)$. No significant differences were found in VAS (back and leg) and ODI scores between techniques at the final follow-up. In our study, we found similar complications in both groups $(11.8 \%$ in open TLIF and $13 \%$ in MIS-TLIF), similar to published reports. Additionally, there was no significant difference found between reoperation rates in both groups. On the other hand, Villavicencio et $\mathrm{al}^{25}$ reported complication rates of $31.6 \%$ in MIS-TLIF and $31.7 \%$ in open TLIF. Their reported complications included infection, malpositioned pedicle screws, neurologic deficit (foot drop), hematoma, conversion of percutaneous to open technique, and leaks of cerebrospinal fluid. We also found similar types of complications in our series; however, none of the patients had to convert from a percutaneous technique to an open technique. However, $2.7 \%$ of patients from open TLIF and $7.2 \%$ of patients from MIS-TLIF had to undergo revision surgeries in our series. The difference was not statistically significant.

Regarding sagittal parameters, we compared 3 parameters-lumbar lordosis, PI, and focal lordosis - at the index level in both groups. In our study, the values of preoperative, postoperative, and final PI angle were approximately same $(P=.584$ for open TLIF and $P=.472$ for MIS-TLIF), which supports the statement that the PI is a fixed angle for the same person. ${ }^{40,41}$ The effect on PI has been investigated in our series with TLIF procedures. Similar preoperative, postoperative, and final PI values further emphasize the fact that PI acquired during individual development is definitively stabilized in adults. ${ }^{42}$ Carlson et $\mathrm{al}^{43}$ found average preoperative lumbar lordosis to be $39.6^{\circ}$, which improved to $45.0^{\circ}$ postoperatively with a difference 
of $5.2^{\circ}$, and, similarly, average preoperative segmental lordosis was $12.7^{\circ}$, which improved to $15.0^{\circ}$ postoperatively with a difference of $2.1^{\circ}$. In our series, we also demonstrated that lumbar lordosis and segmental (focal) lordosis at the index level improved postoperatively with a difference of $3.9^{\circ}$ and $2.5^{\circ}$, respectively, in open TLIF and $4.0^{\circ}$ and $2.9^{\circ}$, respectively, in MIS-TLIF (Table 3). This also proves that the majority of the lordosis gets corrected at the index level with the TLIF procedure. We agree that we have excluded those patients who had significant coronal or sagittal deformities preoperatively, and therefore we recommend further studies, especially in patients with significant coronal or sagittal deformities, to compare the difference in these parameters postoperatively.

\section{CONCLUSIONS}

At present, both MIS-TLIF and open TLIF are widely used surgeries that address degenerative, traumatic, neoplastic, and developmental disorders in the spine. Therefore, comparative study of MISTLIF with open TLIF has been necessary and done in different parts of the world..$^{21,44,45}$ Several metaanalyses have been done on this subject ${ }^{46,47}$; however, such studies in the Indian context are limited. ${ }^{48,49}$ Our study has provided a comprehensive comparative study with a good number of patients and includes a comparative analysis of MIS-TLIF and open TLIF in terms of parameters of sagittal balance. We believe that a large patient population and follow-up of more than 2 years would make it more acceptable. Our study found MIS-TLIF and open TLIF equally effective in correcting lumbar lordosis and focal lordosis. Some studies revealed success in improving segmental lordosis and pelvic tilt; simultaneously, the minimally invasive nature of the approach has raised controversy regarding its capacity to do so. ${ }^{50-52}$ Few studies have proved the superiority of anterior and lateral approaches over TLIF regarding the correction of segmental lordosis and disc height. $^{22,53}$ As this study compared different aspects of MIS-TLIF and open TLIF surgery, the study of other approaches is beyond the scope of this study. Being a comparative study, our study found MIS-TLIF and open TLIF to be equally effective in correcting lumbar lordosis and focal lordosis.

\section{REFERENCES}

1. Phan K, Rao PJ, Kam AC, Mobbs RJ. Minimally invasive versus open transforaminal lumbar interbody fusion for treatment of degenerative lumbar disease: systematic review and meta-analysis. Eur Spine J. 2015;24(5):1017-1030.

2. Mobbs RJ, Phan K, Malham G, Seex K, Rao PJ. Lumbar interbody fusion: techniques, indications and comparison of interbody fusion options including PLIF, TLIF, MI-TLIF, OLIF/ATP, LLIF and ALIF. J Spine Surg. 2015;1(1):218.

3. Harms J, Rolinger H. [A one-stage procedure in operative treatment of spondylolistheses: dorsal traction-reposition and anterior fusion]. Z Orthop Ihre Grenzgeb. 1982;120(3):343-347.

4. Cutler AR, Siddiqui S, Mohan AL, Hillard VH, Cerabona F, Das K. Comparison of polyetheretherketone cages with femoral cortical bone allograft as a single-piece interbody spacer in transforaminal lumbar interbody fusion. J Neurosurg Spine. 2006;5(6):534-539.

5. Houten JK, Post NH, Dryer JW, Errico TJ. Clinical and radiographically/neuroimaging documented outcome in transforaminal lumbar interbody fusion. Neurosurg Focus. 2006;20(3):E8.

6. Potter BK, Freedman BA, Verwiebe EG, Hall JM, Polly DW Jr, Kuklo TR. Transforaminal lumbar interbody fusion: clinical and radiographic results and complications in 100 consecutive patients. J Spinal Disord Tech. 2005;18(4):337-346.

7. Goldstein CL, Phillips FM, Rampersaud YR. Comparative effectiveness and economic evaluations of open versus minimally invasive posterior or transforaminal lumbar interbody fusion: a systematic review. Spine (Phila Pa 1976). 2016;41(suppl 8):S74-S89.

8. Liang Y, Shi W, Jiang C, et al. Clinical outcomes and sagittal alignment of single-level unilateral instrumented transforaminal lumbar interbody fusion with a 4 to 5-year follow-up. Eur Spine J. 2015;24(11):2560-2566.

9. Kim CW, Doerr TM, Luna IY, et al. Minimally invasive transforaminal lumbar interbody fusion using expandable technology: a clinical and radiographic analysis of 50 patients. World Neurosurg. 2016;90:228-235.

10. Foley KT, Holly LT, Schwender JD. Minimally invasive lumbar fusion. Spine (Phila Pa 1976). 2003;28(suppl 15):S26S35.

11. Park Y, Ha JW, Lee YT, Oh HC, Yoo JH, Kim HB. Surgical outcomes of minimally invasive transforaminal lumbar interbody fusion for the treatment of spondylolisthesis and degenerative segmental instability. Asian Spine $J$. 2011;5(4):228-236.

12. Schwender JD, Holly LT, Rouben DP, Foley KT. Minimally invasive transforaminal lumbar interbody fusion (TLIF): technical feasibility and initial results. J Spinal Disord Tech. 2005;18(suppl 18):S1-S6.

13. Lee HJ, Kim JS, Ryu KS. Minimally invasive TLIF using unilateral approach and single cage at single level in patients over 65. Biomed Res Int. 2016;2016:4679865. DOI: 10. $1155 / 2016 / 4679865$

14. $\mathrm{Kim} \mathrm{CH}$, Lee $\mathrm{CH}$, Kim KP. How high are radiationrelated risks in minimally invasive transforaminal lumbar interbody fusion compared with traditional open surgery? A meta-analysis and dose estimates of ionizing radiation. Clin Spine Surg. 2016;29(2):52-59.

15. Nandyala SV, Fineberg SJ, Pelton M, Singh K. 
Minimally invasive transforaminal lumbar interbody fusion: one surgeon's learning curve. Spine J. 2014;14(8):1460-1465.

16. Ryang YM, Villard J, Obermüller T, et al. Learning curve of 3D fluoroscopy image-guided pedicle screw placement in the thoracolumbar spine. Spine J. 2015;15(3):467-476.

17. Park Y, Lee SB, Seok SO, Jo BW, Ha JW. Perioperative surgical complications and learning curve associated with minimally invasive transforaminal lumbar interbody fusion: a single-institute experience. Clin Orthop Surg. 2015;7(1):91-96.

18. Ng CL, Pang BC, Medina PJ, Tan KA, Dahshaini S, Liu LZ. The learning curve of lateral access lumbar interbody fusion in an Asian population: a prospective study. Eur Spine $J$. 2015;24(suppl 3):361-368.

19. Aoki Y, Nakajima A, Takahashi $\mathrm{H}$, et al. Influence of pelvic incidence-lumbar lordosis mismatch on surgical outcomes of short-segment transforaminal lumbar interbody fusion. BMC Musculoskelet Disord. 2015;16:213. doi: 10.1186/ s12891-015-0676-1.

20. Serban D, Calina N, Tender G. Standard versus minimally invasive transforaminal lumbar interbody fusion: a prospective randomized study. Biomed Res Int. 2017;2017 :7236970. doi: 10.1155/2017/7236970.

21. Zhao J, Zhang S, Li X, He B, Ou Y, Jiang D. Comparison of minimally invasive and open transforaminal lumbar interbody fusion for lumbar disc herniation: a retrospective cohort study. Med Sci Monit. 2018;24:86938698. doi: 10.12659/MSM.912808

22. Champagne PO, Walsh C, Diabira J, et al. Sagittal balance correction following lumbar interbody fusion: a comparison of the three approaches. Asian Spine $J$. 2019;13(3):450-458.

23. Seng C, Siddiqui MA, Wong KP, et al. Five-year outcomes of minimally invasive versus open transforaminal lumbar interbody fusion: a matched-pair comparison study. Spine (Phila Pa 1976). 2013;38(23):2049-2055.

24. Kim CH, Easley K, Lee JS, et al. Comparison of minimally invasive versus open transforaminal interbody lumbar fusion. Global Spine J. 2020;10(suppl 2):143S-150S.

25. Villavicencio AT, Burneikiene S, Roeca CM, Nelson EL, Mason A. Minimally invasive versus open transforaminal lumbar interbody fusion. Surg Neurol Int. 2010;1:12. doi: 10. 4103/2152-7806.63905

26. Parker SL, Mendenhall SK, Shau DN, et al. Minimally invasive versus open transforaminal lumbar interbody fusion for degenerative spondylolisthesis: comparative effectiveness and cost-utility analysis. World Neurosurg. 2014;82(1-2):230238.

27. Tian NF, Wu YS, Zhang XL, Xu HZ, Chi YL, Mao FM. Minimally invasive versus open transforaminal lumbar interbody fusion: a meta-analysis based on the current evidence. Eur Spine J. 2013;22(8):1741-1749.

28. Hu W, Tang J, Wu X, Zhang L, Ke B. Minimally invasive versus open transforaminal lumbar fusion: a systematic review of complications. Int Orthop. 2016;40(9):1883-1890.

29. Lin Y, Chen W, Chen A, Li F. Comparison between minimally invasive and open transforaminal lumbar interbody fusion: a meta-analysis of clinical results and safety outcomes. $J$ Neurol Surg A Cent Eur Neurosurg. 2016;77(1):2-10.

30. Hammad A, Wirries A, Ardeshiri A, Nikiforov O, Geiger F. Open versus minimally invasive TLIF: literature review and meta-analysis. J Orthop Surg Res. 2019;14(1):229. doi: 10.1186/s13018-019-1266-y.
31. Sulaiman WA, Singh M. Minimally invasive versus open transforaminal lumbar interbody fusion for degenerative spondylolisthesis grades 1-2: patient-reported clinical outcomes and cost-utility analysis. Ochsner J. 2014;14(1):32-37.

32. Hey HW, Hee HT. Open and minimally invasive transforaminal lumbar interbody fusion: comparison of intermediate results and complications. Asian Spine $J$. 2015;9(2):185-193.

33. Lee JC, Jang HD, Shin BJ. Learning curve and clinical outcomes of minimally invasive transforaminal lumbar interbody fusion: our experience in 86 consecutive cases. Spine (Phila Pa 1976). 2012;37(18):1548-1557.

34. Datta G, Gnanalingham KK, Peterson D, et al. Back pain and disability after lumbar laminectomy: is there a relationship to muscle retraction? Neurosurgery. 2004;54(6):1413-1420; discussion 1420 .

35. Choi WS, Kim JS, Ryu KS, Hur JW, Seong JH. Minimally invasive transforaminal lumbar interbody fusion at L5-S1 through a unilateral approach: technical feasibility and outcomes. Biomed Res Int. 2016;2016:2518394. doi:10.1155/ $2016 / 2518394$

36. Ahn J, Tabaraee E, Singh K. Minimally invasive transforaminal lumbar interbody fusion. J Spinal Disord Tech. 2015;28(6):222-225.

37. Adogwa O, Carr K, Thompson P, et al. A prospective, multi-institutional comparative effectiveness study of lumbar spine surgery in morbidly obese patients: does minimally invasive transforaminal lumbar interbody fusion result in superior outcomes? World Neurosurg. 2015;83(5):860-866.

38. Tay KS, Bassi A, Yeo W, Yue WM. Intraoperative reduction does not result in better outcomes in low-grade lumbar spondylolisthesis with neurogenic symptoms after minimally invasive transforaminal lumbar interbody fusion - a 5-year follow-up study. Spine J. 2016;16(2):182-190.

39. Alamin T, Hardenbrook M, Kim C, et al. Preliminary results of a multicenter randomized study to evaluate the effect of minimally invasive vs. open lumbar fusion on paraspinal musculature using MR imaging. Spine J. 2008;8(suppl 5):8S-9S.

40. Lee JH, Na KH, Kim JH, Jeong HY, Chang DG. Is pelvic incidence a constant, as everyone knows? Changes of pelvic incidence in surgically corrected adult sagittal deformity. Eur Spine J. 2016;25(11):3707-3714.

41. Le Huec JC, Aunoble S, Philippe L, Nicolas P. Pelvic parameters: origin and significance. Eur Spine J. 2011;20(suppl 5):564-571.

42. Marty C, Boisaubert B, Descamps H, et al. The sagittal anatomy of the sacrum among young adults, infants, and spondylolisthesis patients. Eur Spine J. 2002;11(2):119-125.

43. Carlson BB, Saville P, Dowdell J, et al. Restoration of lumbar lordosis after minimally invasive transforaminal lumbar interbody fusion: a systematic review. Spine J. 2019;19(5):951958.

44. Archavlis E, Carvi y Nievas M. Comparison of minimally invasive fusion and instrumentation versus open surgery for severe stenotic spondylolisthesis with high-grade facet joint osteoarthritis. Eur Spine J. 2013;22(8):1731-1740.

45. Luna LM, Sánchez RE, Heredia MAM, Stone KAI, Chiang ES. TLIF-MIS vs TLIF-open: cost evaluation. Coluna/ Columna. 2018;17:138-142.

46. Goldstein CL, Macwan K, Sundararajan K, Rampersaud YR. Perioperative outcomes and adverse events of minimally invasive versus open posterior lumbar fusion: meta- 
analysis and systematic review. Neurosurg Spine. 2016;24(3):416-427.

47. Khan NR, Clark AJ, Lee SL, Venable GT, Rossi NB, Foley KT. Surgical outcomes for minimally invasive vs open transforaminal lumbar interbody fusion: an updated systematic review and meta-analysis. Neurosurgery. 2015;77(6):847-874; discussion 874.

48. Kulkarni AG, Bohra H, Dhruv A, Sarraf A, Bassi A, Patil VM. Minimal invasive transforaminal lumbar interbody fusion versus open transforaminal lumbar interbody fusion. Indian J Orthop. 2016;50(5):464-472.

49. Balasubramanian S, Sonone S, Dahapute A, et al. A comparative prospective study of clinical and radiological outcomes between open and minimally invasive transforaminal lumbar interbody fusion. Indian Spine J. 2019;2(2):138-145.

50. Massie LW, Zakaria HM, Schultz LR, Basheer A, Buraimoh MA, Chang V. Assessment of radiographic and clinical outcomes of an articulating expandable interbody cage in minimally invasive transforaminal lumbar interbody fusion for spondylolisthesis. Neurosurg Focus. 2018;44(1):E8. doi:10. 3171/2017.10.FOCUS17562.

51. Barbagallo GM, Piccini M, Alobaid A, Al-Mutair A, Albanese V, Certo F. Bilateral tubular minimally invasive surgery for low-dysplastic lumbosacral lytic spondylolisthesis (LDLLS): analysis of a series focusing on postoperative sagittal balance and review of the literature. Eur Spine J. 2014;23(suppl 6):705-713.

52. Rajakumar DV, Hari A, Krishna M, Sharma A, Reddy M. Complete anatomic reduction and monosegmental fusion for lumbar spondylolisthesis of Grade II and higher: use of the minimally invasive "rocking" technique. Neurosurg Focus. 2017;43(2):E12. doi:10.3171/2017.5.FOCUS17199.

53. Hsieh PC, Koski TR, O’Shaughnessy BA, et al. Anterior lumbar interbody fusion in comparison with transforaminal lumbar interbody fusion: implications for the restoration of foraminal height, local disc angle, lumbar lordosis, and sagittal balance. J Neurosurg Spine. 2007;7(4):379-386.

Disclosures and COI: There are no relevant financial interests or financial conflicts within the past 5 years and for the foreseeable future. The authors have no financial interests related to the material in the manuscript. There has been no funding support for this study.

Corresponding Author: Hitesh N. Modi, MS, $\mathrm{PhD}$, Spine Surgeon, Department of Spine Surgery, Zydus Hospital, Thaltej, SG Highway, Ahmedabad, Gujarat, India 380054. Phone: +91-8000014464; Email:drmodihitesh@gmail.com.

Published 0 Month 2021

This manuscript is generously published free of charge by ISASS, the International Society for the Advancement of Spine Surgery. Copyright (c) 2021 ISASS. To see more or order reprints or permissions, see http://ijssurgery.com. 